\title{
Avaliação de Três Cultivares de Panicum maximum Jacq. sob Pastejo: Comportamento Ingestivo de Bovinos
}

\section{Patrícia Amarante Brâncio ${ }^{2}$, Valéria Pacheco Batista Euclides ${ }^{3}$, Domicio do Nascimento Junior ${ }^{4}$, Dilermando Miranda da Fonseca ${ }^{4}$, Roberto Giolo de Almeida ${ }^{5}$, Manuel Cláudio Motta Macedo ${ }^{3}$, Rodrigo Amorim Barbosa ${ }^{6}$}

\begin{abstract}
RESUMO - Três cultivares de Panicum maximum Jacq. submetidas a pastejo rotativo foram avaliadas ao longo do ano quanto aos componentes do comportamento ingestivo (tamanho de bocados, tempo de pastejo e taxa de bocados). Os tratamentos constituíram em: 1) cv. Tanzânia $+50 \mathrm{~kg} / \mathrm{ha} \mathrm{de} \mathrm{N,} \mathrm{2)} \mathrm{cv.} \mathrm{Tanzânia}+100 \mathrm{~kg} / \mathrm{ha} \mathrm{de} \mathrm{N,} \mathrm{3)} \mathrm{cv.} \mathrm{Mombaça}+50 \mathrm{~kg} / \mathrm{ha} \mathrm{de} \mathrm{N,} \mathrm{e} \mathrm{4)} \mathrm{cv.} \mathrm{Massai}+50 \mathrm{~kg} / \mathrm{ha}$ de N Os valores do tamanho de bocados foram provavelmente superestimados, mas valores abaixo de $0,300 \mathrm{~g}$ MS/bocado foram observados, considerado crítico, no período seco. Houve tendência a menores bocados na cv. Massai no período seco, provavelmente em função da distribuição de folhas e material morto ao longo do perfil do relvado. Não houve diferenças no tempo de pastejo entre tratamentos e entre épocas de avaliação, mas o padrão de distribuição do tempo gasto pastejando ao longo do dia modificou nas diferentes épocas. Poucas diferenças nas taxas de bocado foram observadas entre cultivares, e no decorrer do período de ocupação dos piquetes, as taxas de bocado tenderam a aumentar. Entre os componentes do comportamento ingestivo observou-se apenas correlação negativa entre tempo de pastejo e tamanho de bocados $(r=-0,45)$.
\end{abstract}

Palavras-chave: tamanho de bocados, taxa de bocados, tempo de pastejo

\section{Evaluation of Three Varieties of Panicum maximum Jacq. under Grazing: Cattle Ingestive Behaviour}

\begin{abstract}
Three varieties of Panicum maximum Jacq. were evaluated by measuring ingestive behavior components (bite size, grazing time, and rate of eating) for one year under rotational grazing. The treatments were: 1) v. Tanzânia $+50 \mathrm{~kg} \mathrm{~N} / \mathrm{ha}, 2$ ) v. Tanzânia $+100 \mathrm{~kg} \mathrm{~N} / \mathrm{ha}, 3) \mathrm{v}$. Mombaça $+50 \mathrm{~kg} \mathrm{~N} / \mathrm{ha}$, and 4) $\mathrm{v}$. Massai $+50 \mathrm{~kg} \mathrm{~N} / \mathrm{ha}$. The values for bite size were probably overestimated, even so, values lower than $300 \mathrm{~g} \mathrm{DM} /$ bite size were observed, a critical consideration, in the dry period. There was a tendency for smaller size bites with v. Massai during the dry period, probably due to distribution of leaves and dead material present in the pasture. There were no differences in time of pasturing among treatments and between seasons of evaluation, but the standard of distribution for time spent grazing along with the day was modified by the different seasons. Few differences in rate of eating were observed among the varieties. The rate of eating tended to increase with the length of time in the plots. Among the components of ingestive behavior the only significant correlation observed was between time of pasturing and bite size $(r=-0.45)$.
\end{abstract}

Key Words: bite size, bite rate, grazing time

\section{Introdução}

Em pastejo rotativo, em especial sob pressões de pastejo médio e alto, ao longo do período de ocupação do piquete, há redução na disponibilidade de forragem e mudanças na estrutura das plantas, principalmente na proporção folha/colmo, que pode afetar de forma severa o comportamento ingestivo e, conseqüentemente, a produção animal (Chacon \& Stobbs, 1976).

$\mathrm{O}$ animal procura manter o consumo e ajusta o comportamento ingestivo em resposta a alguma mudança no meio (Demment \& Greenwood, 1988). A temperatura parece ser o fator do meio mais determinante para o consumo, pois influencia o apetite (Silva \& Leão, 1979) e o comportamento dos animais em pastejo (Manteca \& Smith, 1994), além de afetar de forma indireta o consumo, em virtude de sua influência no valor nutritivo (Wilson \& Ford, 1973; Wilson et al., 1976) e na disponibilidade de forragem (Mota et al., 1981). Van Rees \& Hutson

\footnotetext{
${ }^{1}$ Parte da tese (Doutorado - Zootecnia) do primeiro autor junto à UFV. Pesquisa financiada pela EMBRAPA - Gado de Corte, CAPES e CNPq.

2 Doutora em Zootecnia - UFV. E.mail: pbrancio@zipmail.com.br

${ }^{3}$ Pesquisadores da EMBRAPA - Gado de Corte, Caixa postal 154, CEP: 79002-970, Campo Grande - MS

E.mail: val@cnpgc.embrapa.br; manuel@cnpgc.embrapa.br

4 Professores do Departamento de Zootecnia da UFV, CEP: 36571-000, Viçosa - MG. E mail: domicion@ufv.br; dfonseca@ufv.br

5 Professor do Departamento de Agronomia da UNEMAT, Tangará da Serra, MT, CEP: 78300-000. E.mail: robertogiolo@unemat.br

${ }^{6}$ Estudante de Doutorado em Zootecnia da UFV, CEP: 36571-000, Viçosa - MG. E.mail: guga@vicosa.mail.ufv.br
} 
(1983) atribuíram à influência da temperatura o pastejo intenso dos animais nas horas mais frescas do dia, no início da manhã e no final da tarde. Ainda estes autores verificaram que no verão os animais pastejaram duas a três horas no período noturno, evitando as horas quentes do dia.

Considerando os fatores que influenciam o comportamento ingestivo de animais em pastejo, relacionados ao animal, às plantas, ao meio ambiente e ao manejo, o estudo do comportamento em pastejo parece ter grandes perspectivas de utilização, pois em geral não necessitam de equipamentos caros e sofisticados e não dependem de análises laboratoriais complexas. Ademais, além de ser utilizado como método alternativo para estimar o consumo de forragem (Chacon et al., 1976), auxilia no entendimento de como os animais ajustam este comportamento em função das variações observadas no pasto e no meio ambiente. Segundo Erlinger et al. (1990), possibilita ainda definir as características dos animais e do relvado que influenciam o consumo e fornece informações sobre as relações causais entre forragem e animal que controlam a resposta de ambos.

Objetivou-se, com esta pesquisa, avaliar as variações nos componentes do comportamento ingestivo (tamanho de bocado, tempo de pastejo e taxa de bocado), em quatro pastagens com cultivares de Panicum maximum Jacq. (cv. Tanzânia com dois níveis de nitrogênio; cv. Mombaça e cv. Massai), ao longo do ano, relacionando-as com as características quantitativas e qualitativas do pasto.

\section{Material e Métodos}

Utilizou-se uma área total de 6 ha, pertencente à EMBRAPA Gado de Corte, em Campo Grande, MS, dividida em quatro piquetes de 1,5 ha (umpor tratamento), submetidos a pastejo rotativo, com um período de utilização de sete dias e um período de descanso de 35 dias; os piquetes foram subdivididos em seis áreas de 0,25 ha. Os quatro tratamentos consistiram em: 1 - cv. Tanzânia + 50 kg/ha de N; 2 - cv. Tanzânia com adubação adicional à de manutenção, totalizando $100 \mathrm{~kg} /$ ha de $\mathrm{N}$ (Tanzânia $+100 \mathrm{~kg} /$ ha de N); 3 - cv. Mombaça $+50 \mathrm{~kg} /$ ha de N; e 4 - cv. Massai $+50 \mathrm{~kg} / \mathrm{ha} \mathrm{de} \mathrm{N}$.

Foram utilizados novilhos Nelore de aproximadamente seis meses de idade e peso médio inicial de $150 \mathrm{~kg}$. Cada piquete foi pastejado por quatro bovinos, denominados animais-teste, e por animais adicionais, que foram colocados e removidos de acordo com a disponibilidade de forragem, para que houvesse resíduo pós-pastejo de, aproximadamente, 2,0-2,5 t/ha de matéria seca. Água e sal mineral foram fornecidos à vontade ao longo de todo o período.

As amostragens foram realizadas em junho, setembro e novembro de 1998 e março de 1999.

Para avaliar os tamanhos de bocados, foram utilizados quatro novilhos da raça Nelore fistulados no esôfago, com peso médio inicial de $176 \mathrm{~kg}$, havendo rodízio destes, de forma que cada animal realizasse a amostragem em todos os quatro tratamentos. Assim, realizou-se a amostragem em quatro dias alternados, dentro de um período de utilização da pastagem de sete dias. A ordem dos animais nos piquetes foi determinada mediante sorteio, e durante este período, um animal adicional foi retirado e substituído pelo fistulado.

Os animais fistulados foram submetidos a um jejum de aproximadamente 12 horas antes da amostragem, permanecendo em um cercado sem vegetação, com água à vontade. No início da manhã, em torno de 5-6 horas, as cânulas foram retiradas e as bolsas coletoras foram colocadas nos animais. O período de pastejo destes animais foi de aproximadamente 30 minutos, e foram acompanhados de perto por observadores que registravam todos os bocados realizados. Após a amostragem, os animais foram conduzidos novamente para o cercado, para a retirada das bolsas e colocação das cânulas, sendo posteriormente soltos nos respectivos piquetes.

Os tamanhos de bocado foram estimados na ocasião da amostragem da dieta pelos animais fistulados. Cada animal fistulado no esôfago foi acompanhado por um observador, que, com o auxílio de um contador manual, registrou todos os bocados de preensão de forragem, durante todo o período de pastejo do animal, que foi de aproximadamente 30 minutos. O tamanho de bocado consistiu no peso de matéria seca total do material colhido pelo animal fistulado, dividido pelo número de bocado de preensão realizado pelo animal para colher a forragem. O tamanho de bocado médio consistiu na média das quatro estimativas, para cada mês de amostragem.

Foi estimada a percentagem de recuperação de forragem pela fístula, utilizada para corrigir os erros decorrentes da recuperação incompleta na estimativa do tamanho de bocado, após o período de amostragem. Assim, a forragem consumida consistiu na diferença entre a quantidade fornecida e a recusada, em termos de matéria seca. A forragem encontrada na bolsa coletora foi secada e pesada, sendo a

R. Bras. Zootec., v.32, n.5, p.1045-1053, 2003 
percentagem de recuperação de forragem pela fístula estimada da seguinte maneira:

$$
\text { Recuperação }(\%)=\left[\operatorname{Ext}_{\mathrm{r}} * 100\right] /\left[\mathrm{F}_{\mathrm{f}}-\mathrm{F}_{\mathrm{r}}\right]
$$

em que: Recuperação (\%) = percentagem de recuperação de material pela fístula; Ext $_{\mathrm{r}}(\mathrm{g} \mathrm{MS})=$ peso de matéria seca da forragem encontrada na bolsa coletora; $\mathrm{F}_{\mathrm{f}}(\mathrm{g} \mathrm{MS})=$ peso de matéria seca da forragem oferecida para os animais; e $\mathrm{F}_{\mathrm{r}}(\mathrm{g}$ MS) = peso de matéria seca da forragem recusada pelos animais.

O tempo de pastejo foi computado durante seis dias em cada mês de avaliação, utilizando-se aparelhos vibracorder, segundo Stobbs (1970).

Em um mesmo mês de amostragem, para analisar as variações no tempo de pastejo ao longo do período de ocupação dos piquetes pelos animais, consideraram-se como representativos do início, meio e final do período de pastejo, respectivamente, a média do tempo de pastejo dos dois primeiros dias, a média dos dois dias seguintes e a média dos dois últimos dias. Em termos gerais, o tempo de pastejo médio consistiu na média das seis estimativas, para cada mês de amostragem. Quando foi observado algum comportamento estranho do animal com o aparelho, em relação aos demais, os registros foram descartados.

A taxa de bocado, ou seja, o número de bocados realizados por minuto, foi determinada visualmente por dois observadores, no início da manhã e final da tarde, ocasião em que os animais apresentavam pastejo intenso. Cada observador, para cada turno, registrava o número de bocado de todos os animaistestes em três intervalos de um minuto cada, intercalados em tempos variáveis, mas de no mínimo cinco minutos. Os dias de observação da taxa de bocado foram intercalados com os dias de estimação do tamanho de bocado, ou seja, no segundo, quarto e sexto dias de ocupação dos piquetes pelos animais. Estes dias de amostragem foram considerados, respectivamente, como representativos do início, meio e final do período de ocupação dos piquetes.

Foi utilizada a Análise Multivariada com Medidas Repetidas e, de acordo com a significância ou não da interação entre os efeitos do tratamento e época, foi dado um procedimento estatístico apropriado. Quando a interação foi significativa, realizou-se teste de médias (teste Tukey) entre tratamentos dentro de cada época e, quando a interação não foi significativa, realizou-se este mesmo teste de médias entre tratamentos, independentemente da época. O programa SAS (1990) foi utilizado para realização de todos os procedimentos de análise estatística.

\section{Resultados e Discussão}

\section{Tamanho de bocado}

Os tamanhos de bocado, conforme apresentados na Figura 1, foram maiores no início do período chuvoso (novembro), quando comparados às outras épocas. Neste mês de amostragem, conforme resultados discutidos por Brâncio (2000), houve o somatório de fatores favoráveis para seleção de forragem de maior valor nutritivo do pasto, como maiores relações folha/colmo e folha/material morto, bem como maiores digestibilidades e menores teores de fibra em detergentes neutro e ácido, e lignina.

Entre os tratamentos, em setembro e novembro, verificou-se que os animais que pastejaram na cv. Massai realizaram menores bocados $(\mathrm{P}<0,05)$ que nas demais cultivares. A cv. Massai foi a que apresentou uma das maiores participações de material morto e os menores valores nutritivos (com maiores conteúdos de fibra em detergente neutro e menores digestibilidades e teores de proteína bruta). Por outro lado, em março estas características do pasto também foram observadas, enquanto não houve diferenças significativas entre tratamentos $(\mathrm{P}>0,05)$ quanto ao tamanho de bocados. Neste mês, a disponibilidade de material verde foi alta o suficiente para compensar qualquer possível desvantagem desta cultivar.

A tendência a maiores bocados em pastagens de cv. Mombaça em setembro e novembro pode estar associada à menor proporção de material morto, apesar de essa diferença nem sempre ser estatisticamente significativa $(\mathrm{P}<0,05)$.

Outro fator a ser considerado consiste na forma de distribuição do material morto ao longo do estrato

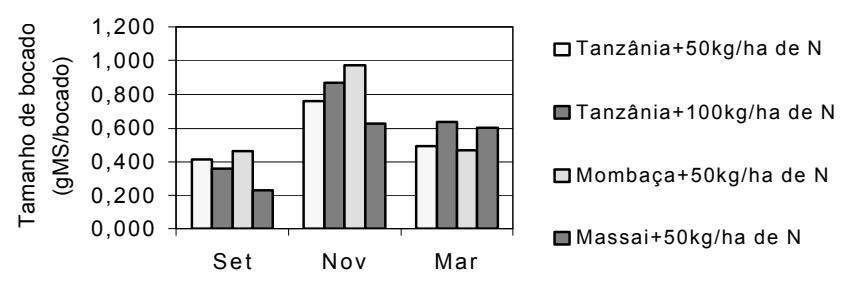

Figura 1 - Tamanho de bocado médio (gMS/bocado) em setembro e novembro de 1998 e março de 1999, em pastagens de cultivares de Panicum maximum Jacq.

Figure 1 - Bite size (gDM/byte) at the beggining (a), midle (b) and end (c) of the ocupation period of the paddocks in september and november of 1998 and march of 1999. 
da pastagem, pois se observou que a cv. Massai tende a apresentar material senescente também entre as folhas verdes, enquanto as outras cultivares tendem a acumular o material morto mais na parte basal da planta, e esta última constitui menor barreira para a seleção do material verde.

Foram estimados os coeficientes de correlação entre o tamanho de bocado (TB) e várias características da pastagem, quantitativas e qualitativas (Brâncio, 2000), com a finalidade de explicar as variações no tamanho de bocado; entretanto, ao se efetuarem os testes de significância, poucas características foram correlacionadas significativamente $(\mathrm{P}<0,05)$. Isto contradiz os relatados de Forbes \& Hodgson (1985), que verificaram correlação negativa entre densidade e TB, e de Burlison et al. (1991) e Penning et al. (1991), que encontraram correlação positiva entre a altura e $\mathrm{TB}$, características que não apresentaram correlações significativas $(\mathrm{P}>0,05)$ neste experimento. A altura parece ter mais influência em pastagens de clima temperado (Forbes, 1988), e a densidade, segundo Hodgson (1985), é de difícil interpretação, pois em geral está correlacionada com a altura. Assim, têm-se encontrado na literatura correlações tanto positivas quanto negativas entre densidade e tamanho de bocado. Segundo os resultados obtidos nesta pesquisa, a percentagem de folhas antes e após o período de ocupação dos piquetes, teve influência marcante sobre o TB $(\mathrm{r}=0,64 \mathrm{e}$ $\mathrm{r}=0,80$, respectivamente). $\mathrm{O}$ teor de $\mathrm{PB}$ na forragem selecionada foi significativamente correlacionado com o TB $(r=0,85, \mathrm{P}<0,05)$, provavelmente devido ao fato dos animais realizarem maiores tamanhos de bocados quando a forragem é tenra, e este tipo de forragem tem, em geral, maior valor nutritivo.

Avaliando o efeito da adubação nitrogenada adicional realizada no final do período chuvoso sobre o tamanho de bocados em pastagem de cv. Tanzânia, não foram verificadas diferenças significativas $(\mathrm{P}>0,05)$, mas sim tendência a maiores bocados na cv. Tanzânia $+100 \mathrm{~kg} / \mathrm{ha}$ de N, concordando com Stobbs (1975), que observou tendência a maiores bocados com aumentos na adubação nitrogenada.

Quando se analisou o tamanho de bocados no início do período de ocupação do piquete (Figura 2), verificou-se que houve tendência a redução do tamanho do bocado realizado ao longo do período de ocupação do piquete. Observou-se que, em geral, os maiores bocados foram realizados quando os animais entravam no piquete. À medida que os animais
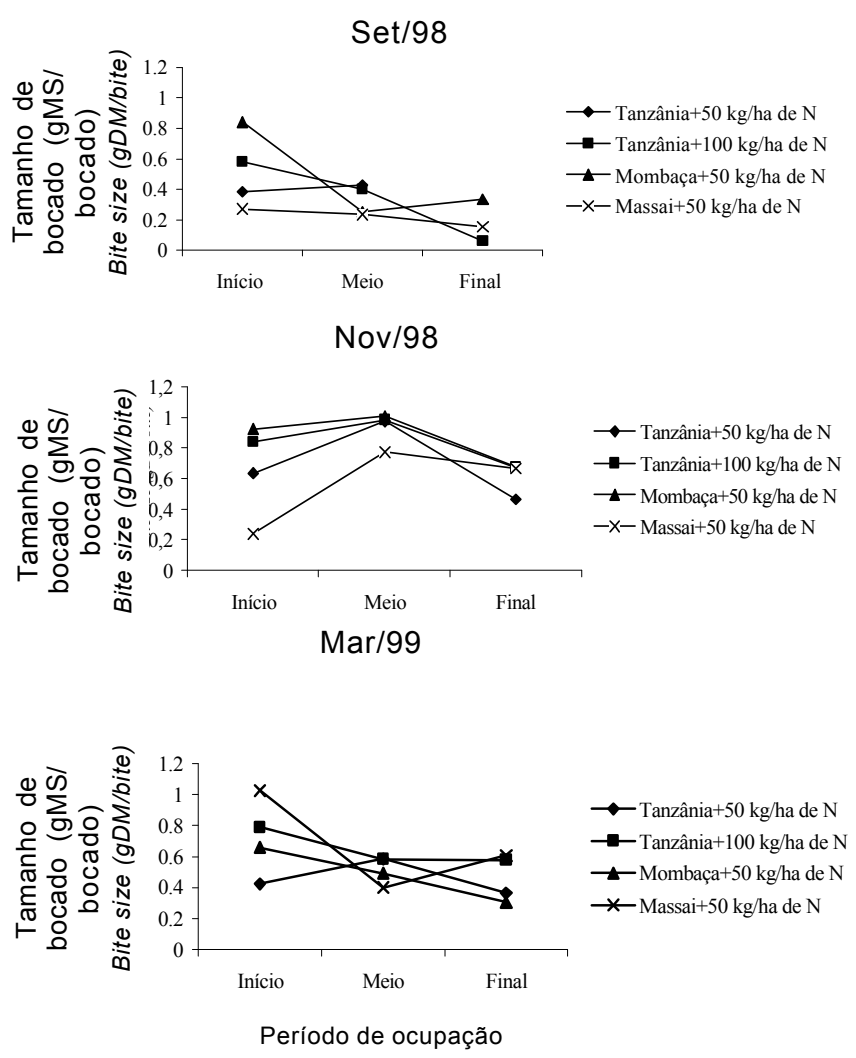

Figura 2 - Tamanho de bocado (gMS/bocado) no início, meio e final do período de ocupação dos piquetes por bovinos, em pastagens de cultivares de Panicum maximum Jacq., em setembro e novembro de 1998 e março de 1999.

Figure 2 - Bite size (gDM/bite) in the beginning, middle (b) and at the end of the grazing period, in pastures of Panicum maximum Jacq. cultivars in September and November of 1998 and March of 1999.

permaneciam pastejando, a estrutura do relvado era modificada (redução da proporção de folhas nos estratos superiores da pastagem), resultando em condições menos favoráveis a realizações de bocados maiores.

Porém, esta mesma tendência não foi observada em novembro. Ressalta-se, entretanto, que estes estudos sobre o tamanho de bocado no início, meio e final do período de ocupação dos piquetes se basearam na amostragem de apenas um animal por tratamento em cada um destes momentos de avaliação, em função da baixa disponibilidade de animais fistulados. Assim, a possível diferença entre animais foi anulada apenas quando se considerou a média de todas as observações ao longo do período de ocupação do piquete.

Um grande problema associado às estimativas do tamanho de bocado consistiu na utilização de animais 
fistulados, que podem apresentar comportamento diferente dos demais, por terem sido submetidos a jejum de aproximadamente 16 horas antes da amostragem.

Outro fator que pode também ter contribuído para a superestimação do tamanho de bocado consistiu na amostragem realizada pela manhã, pois segundo Illius (1989), ocorre declínio no tamanho de bocado ao longo do dia, em razão dos animais estarem dispostos a exercer mais força e aprofundar o bocado, no início do pastejo.

Outro possível problema na estimação do tamanho do bocado utilizando-se animais fistulados consiste na recuperação incompleta do material nas bolsas coletoras. Neste experimento, não foram utilizados tampões ou rolhas para aumentar a recuperação, mas, por ocasião das cirurgias, procurou-se realizar fístulas de diâmetro o maior e o mais ventral possível, conforme recomendado por alguns autores (Forbes, 1988; Carvalho \& Euclides; 1989; Fisher et al., 1989). Ainda, foi efetuada correção para os tamanhos de bocado, estimando-se a porcentagem de recuperação (Tabela 1). Com exceção da recuperação estimada para a cv. Massai em setembro, as recuperações não foram completas, mas apresentaram valores satisfatórios, se comparados aos encontrados por Campbell et al. (1968). Estes autores verificaram recuperação de 26 e $34 \%$ para forragens verdes. Stobbs (1973) encontrou valores entre 28,3 a $88,7 \%$ (média de 62,2\%) sem a utilização de rolha, enquanto com esta técnica as recuperações foram de 89,6 a $101,5 \%$ (média de $95 \%$ ). No entanto, Alder (1969) constatou recuperação de 96 a 104\%, com média de $99,7 \%$. As recuperações variaram com o tratamento e com as épocas de avaliação. Os menores valores foram observados em novembro, período em que a forragem foi em geral mais tenra, o que favorece a passagem direta do material sem cair na bolsa coletora.

Apesar da possibilidade de superestimação das estimativas para tamanhos de bocados, foram encontrados valores inferiores, em especial na cv. Massai, ao valor crítico de $0,300 \mathrm{~g} \mathrm{MO} /$ bocado (Stobbs, 1973), o que corresponde a cerca de 0,330 a $0,350 \mathrm{~g} \mathrm{MS}$ / bocado, de acordo com o percentual de matéria orgânica presente no pasto.

Na literatura, têm-se encontrado valores bastante variáveis de tamanho de bocado; entre outros, Stobbs (1973) encontrou bocados de 0,400 a $0,520 \mathrm{~g}$ $\mathrm{MO} /$ bocado, variando a espécie forrageira de Pangola a Rhodes. Stobbs (1975) encontrou valores de 0,220 a $0,340 \mathrm{gMO} /$ bocado, variando adubação nitrogenada desde a ausência de adubação até $60 \mathrm{~kg} / \mathrm{ha}$ de N; Forbes \& Hodgson (1985) observaram valores de 0,910 a 1,170 mg MO/kg PV, variando a densidade da vegetação de densa para aberta; e Burlison et al. (1991) encontraram tamanhos de bocados de 0,040 a $0,330 \mathrm{~g} \mathrm{MS}$, variando altura.

Tempo de pastejo

Os tempos de pastejo (TP), em termos médios, foram semelhantes estatisticamente $(\mathrm{P}>0,05)$, para todos os tratamentos e épocas de avaliação, apresentando valores entre 498 e 678 minutos diários (Figura 3). Apesar de o animal tentar compensar reduções no tamanho de bocado, devido a alguma dificuldade na preensão de forragem, em períodos menos favoráveis, essa ferramenta parece ser de menor importância, uma vez que variou muito pouco durante o ano, enquanto a pastagem variou em disponibilidade (de 1.500 a $5.000 \mathrm{~kg} / \mathrm{ha}$ de MS), altura (de $20 \mathrm{a} 70 \mathrm{~cm}$ ), profundidade de pastejo (de 10 a $35 \mathrm{~cm}$ ) e em percentagens de folha (de 30 a $60 \%)$, colmo (5 a $25 \%$ ) e material morto (de 20 a $55 \%$ ). O tempo de pastejo não foi correlacionado com o tamanho de

Tabela 1 - Percentagem de recuperação de forragem consumida por animais fistulados, nas bolsas coletoras, em junho, setembro e novembro de 1998 e março de 1999.

Table 1 - Percentage of ingested forage recovered by esophageal fistulated animals, in june, september and november of 1988 and march of 1999.

\begin{tabular}{lcccc}
\hline $\begin{array}{l}\text { Cultivares } \\
\text { Cultivars }\end{array}$ & \multicolumn{3}{c}{$\begin{array}{c}\text { Meses } \\
\text { Months }\end{array}$} \\
\cline { 2 - 5 } & Jun./98 & Set./98 & Nov./98 & Mar./99 \\
& Jun./98 & Sep./98 & 74,8 & Mar./98 \\
\hline Tanzânia $+50 \mathrm{~kg} / \mathrm{ha} \mathrm{de} \mathrm{N}$ & - & 76,8 & 74,4 & 80,2 \\
Tanzânia $+100 \mathrm{~kg} / \mathrm{ha} \mathrm{de} \mathrm{N}$ & - & 87,5 & 65,7 & 91,5 \\
Mombaça $+50 \mathrm{~kg} / \mathrm{ha} \mathrm{de} \mathrm{N}$ & - & 84,4 & 68,0 & 82,0 \\
Massai $+50 \mathrm{~kg} / \mathrm{ha} \mathrm{de} \mathrm{N}$ & - & 103,2 & & \\
\hline
\end{tabular}

R. Bras. Zootec., v.32, n.5, p.1045-1053, 2003 


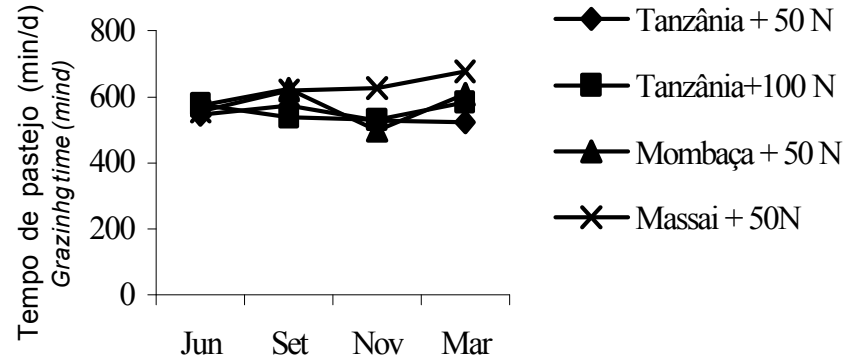

Figura 3 - Tempo de pastejo ( $\mathrm{min} / \mathrm{d}$ ) em pastagens de cultivares de Panicum maximum Jacq., em junho, setembro e novembro de 1998 e março de 1999.

Figure 3 - Grazing time $(\mathrm{min} / \mathrm{d})$ in pastures of Panicum maximum Jacq. cultivars in June, September and November of 1998 and March of 1999.

bocado, pois o valor de $-0,45$ não foi significativo $(\mathrm{P}>0,05)$. Nenhuma característica quantitativa da pastagem foi significativamente correlacionada $(\mathrm{P}>0,05)$ com o tempo de pastejo, indicando que as características estruturais parecem ter pouca influência no tempo de pastejo. Contrariamente aos dados da literatura, a disponibilidade e a altura não foram correlacionadas com o tempo de pastejo (Castle et al., 1975; Penning et al., 1991).

Das características qualitativas, no início da ocupação dos piquetes, apenas o teor de lignina da forragem foi significativamente correlacionado $(r=0,51, \mathrm{P}<0,05)$. Enquanto no final do período de ocupação dos piquetes, o valor nutritivo da forragem pareceu ter mais influência sobre o tempo de pastejo, verificando-se correlações negativas entre o TP e o teor de proteína bruta $(\mathrm{r}=-0,51$, $\mathrm{P}<0,05)$ e entre o TP e a digestibilidade $(\mathrm{r}=-0,60$, $\mathrm{P}<0,05)$. Isto pode ser atribuído ao fato de os animais necessitarem de mais tempo quando a forragem é de baixo valor nutritivo, para satisfazer seus requerimentos em nutrientes, principalmente se os tamanhos de bocado forem reduzidos.

Ao observar a curva do tempo de pastejo gasto ao longo do dia, verifica-se que o padrão se modifica ligeiramente ao longo do ano (Figura 4). Isto ocorre em razão das variações climáticas nas épocas de avaliação.

O tempo de pastejo noturno, portanto, esteve dentro do previsto, pois, segundo relatado por outros autores, o animal realiza pastejo à noite, de $10 \mathrm{a} 70 \%$ do tempo total diário (Krysl \& Hess, 1993). Ebersohn et al. (1983), por exemplo, verificaram que 12 a $27 \%$ do pastejo foi realizado à noite, e Boneli (1988) verificou $11,4 \%$ do pastejo total diário no período noturno, considerado de 21 às 5 h. No horário de 14 às $17 \mathrm{~h}$ ocorreu a maior parte do pastejo, principalmente nas duas primeiras épocas de avaliação, estando de acordo com Penning et al. (1991), que reportaram consumo preferencial há cerca de quatro horas antes do pôr-do-sol, atribuído à maior concentração de sacarose nas folhas das gramíneas. O início da manhã foi o segundo período preferido pelos animais para o pastejo, e das 20 às $23 \mathrm{~h}$ foi, em geral, o terceiro na preferência dos animais. Van Rees \& Hutson (1983) verificaram pastejo intensivo nas quatro primeiras horas do dia, mas também observaram o mesmo no final da tarde, enquanto durante à tarde os animais pastejaram de forma intermitente. Segundo McDowell (1972), citado por Van Soest (1994), os animais pastejam acentuadamente em torno das 18 às $20 \mathrm{~h}$, quando as temperaturas são superiores a $25^{\circ} \mathrm{C}$, por serem períodos mais frescos do dia, enquanto em temperaturas inferiores eles pastejam de forma mais distribuída ao longo do dia. Esse padrão não foi observado, pois no período chuvoso, correspondente a temperaturas altas, os animais apresentaram tempo de pastejo mais bem distribuído durante o dia, principal-mente no início do período chuvoso. Em todos os períodos, os animais não evitaram as horas quentes do dia, como esperado, chegando a pastejar cerca de $10 \%$ do tempo total de 11 às $14 \mathrm{~h}$, período inclusive escolhido para troca do vibracorder (13-14h). Este horário de troca foi escolhido com base em observações anteriores ao início do experimento, quando foi verificado que, em geral, os animais permaneciam parados sistematicamente neste horário. Outro fator a ser considerado consiste na utilização de animais zebuínos no experimento, os quais, segundo Manteca \& Smith (1994) e Shankar \& Singh (1996), são pouco afetados por temperaturas mais elevadas, uma vez que apresentam glândulas sudoríparas maiores, mais ativas e mais numerosas, quando comparados à maioria das raças européias.

O tempo gasto em pastejo diário do início para o final do período de ocupação tende a crescer, pois em pastejo rotativo grande parte das características do pasto se modifica ao longo da semana de pastejo, principalmente altura da pastagem e proporção de material morto. Em média, os animais passaram 527, 583 e 610 minutos em pastejo, respectivamente no início, meio e final do período de ocupação do piquete. Mudanças no comportamento ingestivo em função de modificações na estrutura do relvado ao longo do período de ocupação do piquete, em pastejo rotativo, 
Jun/98
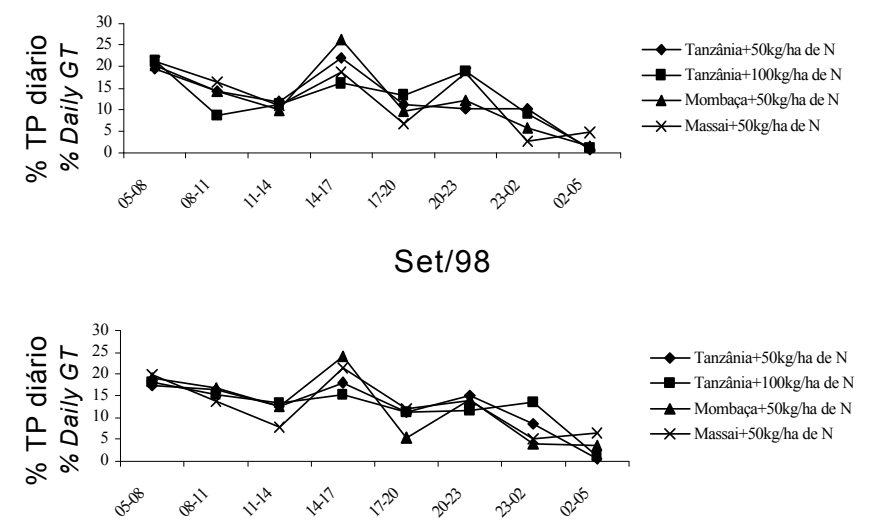

Nov/98
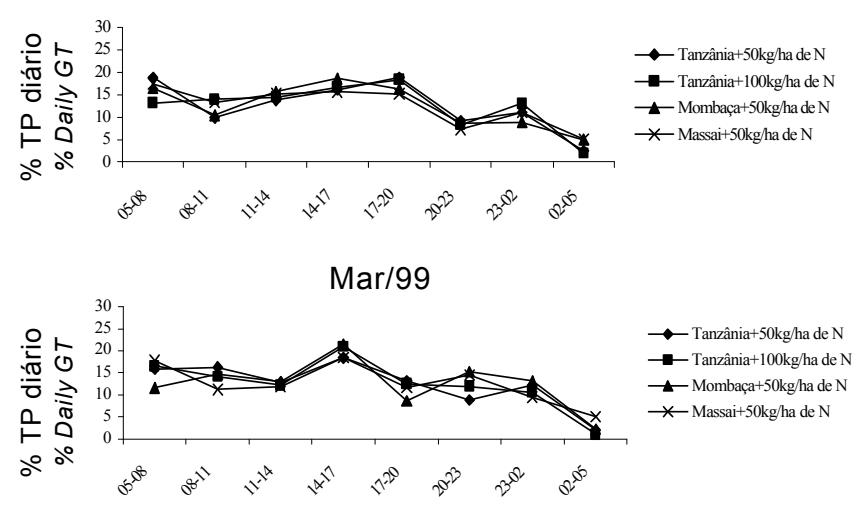

Período do dia

Figura 4 - Percentual de tempo de pastejo (TP) ao longo do dia, em pastagens de cultivares de Panicum maximum Jacq. Em junho, setembro, e novembro de 1998 e março de 1999.

Figure 4 - Percentage of grazing time during the day, in pastures of Panicum maximum Jacq. cultivars, in June, September and November of 1998 and March of 1999.

também foram reportadas por outros autores (Chacon \& Stobbs, 1976). Apesar de os dados obtidos para análise da variação no tempo de pastejo ao longo do período de ocupação serem provenientes da informação de um ou dois animais por piquete, podem ser considerados sem restrições, pois os animais pastejam de forma sincronizada (Rook \& Huckle, 1995).

Taxa de bocados

A taxa de bocado, ou seja, o número de bocados que o animal realiza por minuto, tendeu a ser um pouco maior no final da época seca (cv. Tanzânia + $100 \mathrm{~kg} / \mathrm{ha}$ de N e cv. Massai) ou no início da época chuvosa (cv. Tanzânia $+50 \mathrm{~kg} / \mathrm{ha}$ de $\mathrm{N}$ e cv. Mombaça) (Figura 5). A pouca variação nas taxas de bocado observada durante o experimento corrobora a idéia de que estas constituem uma ferramenta ineficaz para com-pensar mudanças no tamanho de bocado. Neste experimento, as correlações entre a taxa de bocado e o tamanho de bocado, bem como entre a taxa de bocado e o tempo de pastejo, foram estatisticamente não significativas $(\mathrm{P}>0,05)$.

$\mathrm{O}$ grau de relacionamento entre a taxa de bocado (TX) e as características do pasto foi estudado. Apenas a relação folha/colmo foi correlacionada significativamente com a taxa de bocados $(r=0,65$, $\mathrm{P}<0,05)$. Esses resultados foram de difícil interpretação, pois em geral a taxa de bocado e o tamanho de bocado estão correlacionados negativamente, e espera-se que, quanto maior a disponibilidade e acessibilidade de folhas, maior o tamanho de bocado e, como conseqüência, maior a necessidade de tempo para a acomodação da forragem na boca do animal, restringindo a realização de mais bocados por minuto (Hodgson, 1990). Entretanto, a relação folha/colmo e a taxa de bocado foram positivamente correlacionadas, o que significa que, quando a acessibilidade das folhas foi menor, os animais apresentaram menores taxas de bocado, o que teria como possível explicação o fato de que, com piores condições para seleção do material preferido, o animal reduziria o tempo de permanência em cada estação alimentar, e o número de bocado por estação também reduziria (Roguet et al., 1998). Nestes casos, o pastejo seria menos intensivo, pois os animais gastariam mais tempo selecionando a forragem preferida. Contudo, esta explicação não é satisfatória, pois, ao se analisar em cada época, ao longo do período de ocupação (Figura 6), quando as características do pasto ficam crescentemente desfavoráveis a seleção de folhas, a taxa de bocado tende a aumentar. Acredita-se, portanto, que os resultados observados foram devidos à maior variação entre épocas que entre tratamentos, apresentando maior taxa de bocado na época em que o pasto era melhor. Dentro de cada época, porém, a taxa de bocados foi maior quando as condições do pasto eram piores.

Poucas diferenças significativas entre tratamentos foram encontradas. Em junho, os tratamentos foram semelhantes, enquanto em setembro os animais que pastejaram na cv. Massai realizaram mais bocados que aqueles na cv. Tanzânia $+100 \mathrm{~kg} /$ ha de $\mathrm{N}$ e na cv. Mombaça. Nesta ocasião, a cv. Massai apresentava relação folha/colmo superior à das demais cultivares, mas 


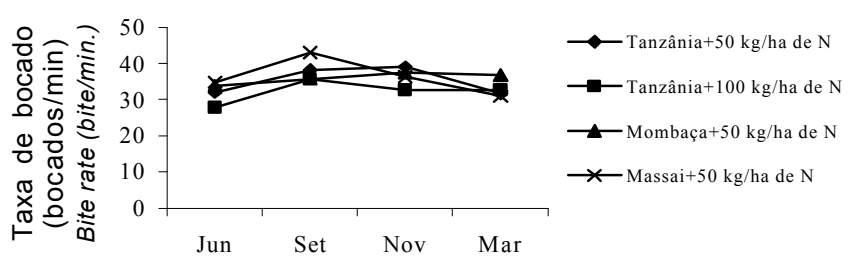

Figura 5 - Taxa de bocados (bocados/min) realizada por bovinos em pastagens de cultivares de Panicum maximum Jacq., em junho, setembro e novembro de 1998 e março de 1999.

Figure 5 - Bite rate (bite/min) by grazing animals in pastures of Panicum maximum Jacq. cultivars in June, September and November of 1998 and March of 1999. também observou-se tendência de maior proporção de material morto; a forma mais distribuída do material morto, entrelaçado a folhas verdes, em que este se apresentava no pasto, constituiu uma maior barreira para preensão de forragem. Ademais, o tamanho de bocado foi menor na cv. Massai que nas outras cultivares. Apesar de isoladamente esses fatores não serem correlacionados de maneira significativa $(\mathrm{P}>0,05)$, em conjunto, podem ter alterado o comportamento ingestivo. Em novembro, a cv. Tanzânia + $50 \mathrm{~kg} / \mathrm{ha}$ de $\mathrm{N}$ e a cv. Mombaça não diferiram $(\mathrm{P}>0,05)$ da cv. Massai e foram superiores $(\mathrm{P}<0,05)$ à cv. Tanzânia $+100 \mathrm{~kg} / \mathrm{ha}$ de $\mathrm{N}$. Em março, a cv. Mombaça foi superior $(\mathrm{P}<0,05)$ à cv.

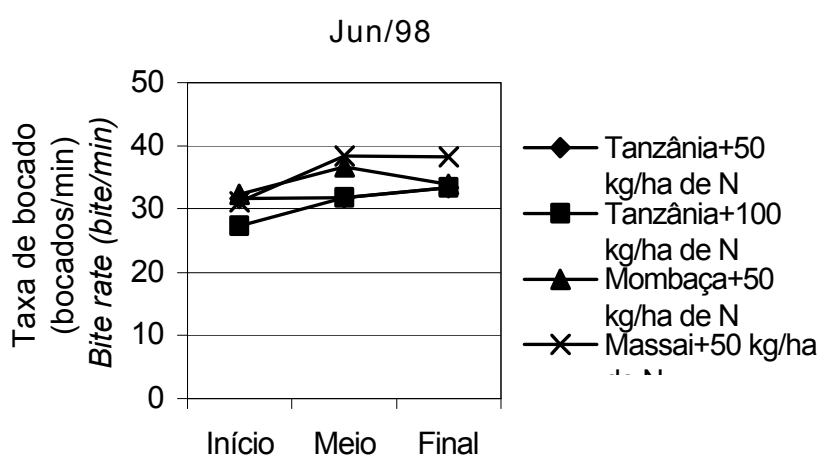

Nov/98

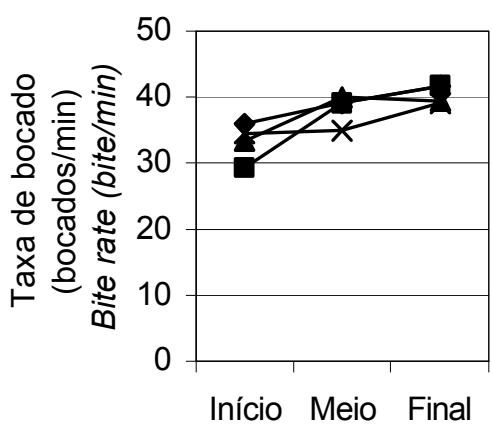

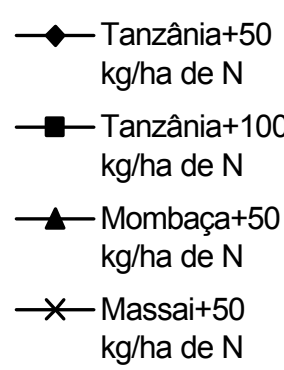
$\mathrm{kg} / \mathrm{ha}$ de $\mathrm{N}$

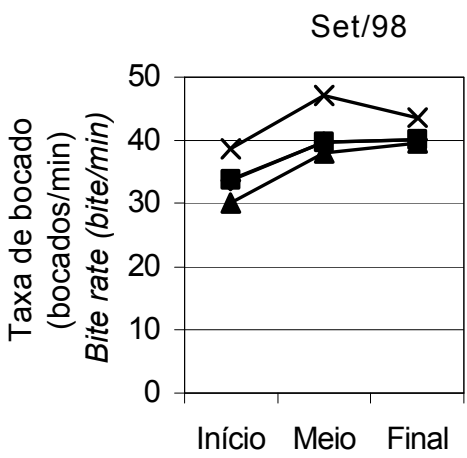

- Tanzânia+50 $\mathrm{kg} / \mathrm{ha}$ de $\mathrm{N}$

- Tanzânia+100 $\mathrm{kg} / \mathrm{ha}$ de $\mathrm{N}$

- - Mombaça+50 $\mathrm{kg} / \mathrm{ha}$ de $\mathrm{N}$

$\rightarrow$ Massai+50 $\mathrm{kg} / \mathrm{ha}$ de $\mathrm{N}$

Mar/99

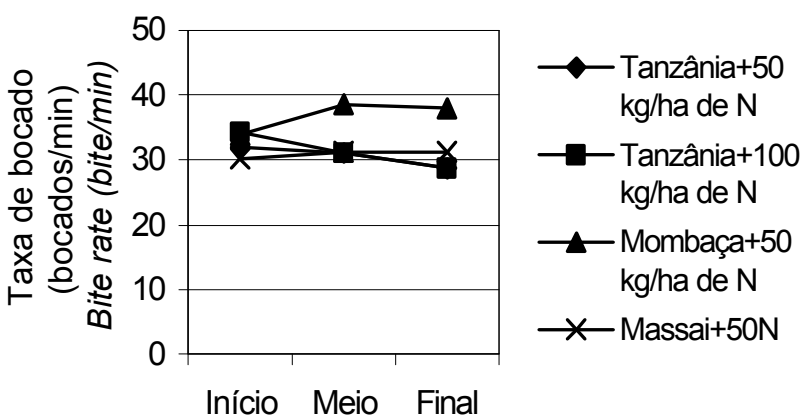

Figura 6 - Taxa de bocado (bocados/minutos) realizada por bovinos no início, meio e final do período de ocupação dos piquetes, em junho, setembro e novembro de 1998 e março de 1999.

Figure 6 - Bite rate (bite/min) .by grazing animals in the beginning, midle and end of grazing periods.in pastures of Panicum maximum Jacq. cultivars in June, September and November of 1998 and March of 1999.

Tanzânia $+50 \mathrm{~kg} / \mathrm{ha}$ de $\mathrm{N}$ e à cv. Massai.

Os números de bocados encontrados neste estudo estão dentro da faixa de valores encontrada na literatura (Erlinger et al., 1990).

\section{Conclusões}

No período seco os tamanhos de bocado foram reduzidos, o que poderia limitar o consumo total de 
forragem pelos animais nesta época.

Os animais modificaram o padrão de distribuição do tempo de pastejo ao longo do dia nas diferentes épocas, mas o tempo de pastejo total diário pouco variou.

Dos tratamentos, a cv. Massai apresentou resultados inferiores para tamanhos de bocado no período seco, bem como as maiores taxas de bocado, mas esta tendência não permaneceu na época chuvosa.

As mudanças ocorridas no pasto ao longo do período de ocupação do piquete foram desfavoráveis a seleção da forragem preferida, uma vez que houve redução dos tamanho dos bocados e aumento do tempo de pastejo e da taxa de bocados.

\section{Literatura Citada}

BONELI, I.B. Estimativas do consumo de matéria orgânica e determinação da atividade de pastejo com bovinos em pastagem nativa melhorada. Porto Alegre: Universidade Federal do Rio Grande do Sul, 1988. 236p. Dissertação (Mestrado em Zootecnia) - Universidade Federal do Rio Grande do Sul, 1988.

BRÂNCIO, P.A Comportamento animal e estimativas de consumo por bovinos em pastagens de Panicum maximum Jacq. (Cultivares Tanzânia, Mombaça e Massai). Viçosa, MG: Universidade Federal de Viçosa, 2000. 277p. Tese (Doutorado em Zootecnia) - Universidade Federal de Viçosa, 2000.

BURLISON, A.J.; HODGSON, J.; ILLIUS, A.W. Sward canopy structure and the bite dimension and bite weight of grazing sheep. Grass and Forage Science, v.46, p.29-38, 1991.

CAMPBELL, C.M.; ENG JR, K.S.; NELSON, A.B.; POPE, L.S. Use of the esophageal fistula in diet sampling with beef cattle. Journal of Range Management, v.27, n.1, p.231-234, 1968.

CARVALHO, E.G.; EUCLIDES, V.P.B. Preparo de fístula esofágica para recuperação máxima do alimento ingerido. Pesquisa Agropecuária Brasileira, v.24, n.10, p.1241-47, 1989.

CHACON, E.; STOBBS, T.H. Influence of progressive defoliation of a grass sward on the eating behaviour of cattle. Australian Journal Agricultural Research, v.27, p.709-727, 1976.

CHACON, E.; STOBBS, T.H.; SANDLAND, R.L. Estimation of herbage consumption by cattle using measurements of eating behaviour. Journal of British Grassland Society, v.31, p.81-87, 1976.

DEMMENT, M.W.; GREENWOOD, G.B. Forage ingestion: effects of sward characteristics and body size. Journal of Animal Science, v.66, p.2380-2392, 1988.

EBERSOHN, J.P.; EVANS, J.; LIMPUS, J.F. Grazing time and its diurnal variation in beef steers in coastal South-East Queensland. Tropical Grassland, v.17, n.2, p.76-81, 1983.

ERLINGER, L.L.; TOLLESON, D.R.; BROWN, C.J. Comparison of bite size biting rate and grazing time of beef heifers from herds distinguished by mature size and rate of maturity. Journal of Animal Science, v.68, p.3578-3587, 1990.

FISHER, D.S.; BURNS, J.C.; POND, K.R. Esophageal plug and fasting effects on particle size distribution and quality of extrusa from grass pastures. Agronomy Journal, v.81, p.129-132, 1989.

FORBES, T.D.A.; HODGSON, J. Comparative studies of the influence of sward conditions on the behavior of cows and sheep. Grass and Forage Science, v.40, p.69-77, 1985.
FORBES, T.D.A. Researching the plant animal interface: the investigation of ingestive behavior in grazing animals. Journal of Animal Science, v.66, p.2369-2379, 1988.

HODGSON, J. The control of herbage intake in the grazing ruminant. Proceedings of the Nutrition Society, v.44, p.339-346, 1985.

HODGSON, J. Grazing management - science into practice. New York: Longman Handbook in Agriculture, 1990. 203p.

ILLIUS, A.W. Allometry of food intake and grazing behavior with body size in cattle. Journal of Agriculture Science, v.113, p.259-266, 1989.

KRYSL, L.J.; HESS, B.W. Influence of supplementation on behaviour of grazing cattle. Journal of Animal Science, v.71, p.2546-2555, 1993.

MANTECA, X.; SMITH, A.J. Effects of poor forage conditions on the behaviour of grazing ruminants. Tropical Animal Health and Production, v.26, p.129-138, 1994.

MOTA, F.S.; BERNY, Z.B.; MOTA, J.F.A.S. Índice climático de crescimento de pastagens naturais no Rio Grande do Sul. Pesquisa Agropecuária Brasileira, v.16, n.4, p.453-472, 1981.

PENNING, P.D.; PARSONS, A.J.; ORR, R.J.; TREACHER, T.T. Intake and behaviour responses by sheep to changes in sward characteristics under continuous stocking. Grass and Forage Science, v.46, p.15-28, 1991.

ROGUET, C.; PRACHE, S.; PETIT, M. Feeding station behaviour of ewes in response to forage availability and sward phonological stage. Applied Animal Behavior Science, v.56, p.187-201, 1998.

ROOK, A.J.; HUCKLE, C.A. Synchronization of ingestive behaviour by grazing dairy cows. Animal Science, v.60, p.25-30, 1995.

SAS INSTITUTE SAS/STAT. User's guide statistics, Versão 6, 4.ed., Cary: 1990. 846p.

SHANKAR, V.; SINGH, J.P. Grazing ecology. Tropical Ecology, v.37, n.1, p.67-78, 1996.

SILVA, J.F.C.; LEÃO, M.I. Fundamentos de nutrição dos ruminantes. Piracicaba: Livroceres, 1979. 384p.

STOBBS, T.H. The effect of plant structure on the intake of tropical pastures. I. Variation in the bites size of the grazing cattle. Australian Journal of Agricultural Research, v.24, n.6, p.809-819, 1973.

STOBBS, T.H. The effect of plant structure on the intake of tropical pastures. III. Influence of fertilizer nitrogen of the size of bite harvested by jersey cows grazing Setaria anceps cv. kazungula swards. Australian Journal of Agricultural Research, v.26, p.997-1007, 1975.

Van REES, H.; HUTSON, G.D. The behaviour of free-ranging cattle on an alpine range in Australia. Journal of Range management, v.36, n.6, p.740-743, 1983.

Van SOEST, P.J. Nutritional ecology of the ruminant. 2.ed. Ithaca: Cornell University Press, 1994. 476p.

WILSON, J.R.; FORD, C.W. Temperature influences on the in vitro digestibility and soluble carbohydrate accumulation of tropical and temperate grasses. Australian Journal of Agricultural Research, v.24, p.187-198, 1973.

WILSON, J.R.; TAYLOR, A.O.; DOLBY, G.R. Temperature and atmospheric humidity effects on cell wall content and dry matter digestibility of some tropical and temperate grasses. New Zealand Journal Agriculture Research, v.19, p.41-46, 1976.

R. Bras. Zootec., v.32, n.5, p.1045-1053, 2003

Recebido em: 05/07/02 Aceito em: 21/11/02 